\title{
A DEMOCRACIA COMO PREMISSA FUNDAMENTAL PARA O DESENVOLVIMENTO: Crítica à Ideia de Expansão das Liberdades em um Ambiente Não Democrático
}

\author{
Maria Cristina Cruz Lima \\ Autora correspondente. http://lattes.cnpq.br/5942148710424364. https://orcid.org/0000-0003-0861-814X. lima.tina@gmail.com

\section{Daniel Fernando Pastre} \\ Pontifícia Universidade Católica do Paraná (PUC-PR). http://lattes.cnpq.br/4039604215827423. \\ https://orcid.org/0000-0002-5935-0457. daniel.pastre@gmail.com
}

Este artigo aborda a democracia e o desenvolvimento, objetivando avaliar a noção de desenvolvimento a partir das lições de Amartya Sen, conectando-o ao de democracia, a fim de estabelecer uma crítica à possibilidade de expansão das liberdades em um ambiente institucional não (ou menos) democrático. Para tanto, a opção metodológica foi pelo método dedutivo e a conclusão final é por rejeitar a tese de que é possível, quiçá mais viável, gerar desenvolvimento em países não (ou menos) democráticos.

Palavras-chave: Democracia; desenvolvimento; Amartya Sen; expansão das liberdades.

DEMOCRACY AS A FUNDAMENTAL PREMISE FOR DEVELOPMENT:

CRITIC OF THE EXPANSION OF LIBERTIES THEORY IN A NON-DEMOCRATIC ENVIRONMENT

\section{ABSTRACT}

The purpose of this article is to evaluate the concept of development from the lessons of Amartya Sen, connecting it to the concept of democracy, in order to establish a critique of the possibility of expanding liberties in a non (or less) democratic environment. To do so, the methodological option was by the deductive method and the final conclusion is to reject the thesis that it is possible, perhaps more viable, to generate development in non (or less) democratic countries.

Keywords: Democracy; development; Amartya Sen; expansion of liberties. 


\section{INTRODUÇÃO}

A noção de desenvolvimento como liberdade, como será visto a partir da obra de Amartya Sen, estabelece que os valores democráticos (como a liberdade civil e a liberdade política) são meios e, ao mesmo tempo, fins para a noção de desenvolvimento. Essas liberdades atuam como pressupostos instrumentais que, ao se expandirem, retroalimentam todo o sistema de liberdades, incrementando-os, gerando também um maior índice de bem-estar dos cidadãos.

Existem atualmente, contudo, diversas críticas lastreadas especialmente na verificação empírica de que é possível, mesmo em países não (ou menos) democráticos, conseguir níveis de crescimento econômico (a expansão das liberdades econômicas, portanto) por vezes maiores que em países democráticos (BHAGWATI, 2002, p. 151-162), sendo questionável nesses casos se a própria democracia (ou as liberdades civis e políticas) não é um obstáculo ao desenvolvimento ou se é possível aplicar-se uma noção de desenvolvimento em ambientes não (ou menos) democráticos, ou ainda se é possível falar de uma hierarquia entre as liberdades (civis e políticas em contraposição às liberdades e facilidades econômicas).

Assim, para concretização dessa proposta a opção foi pela divisão do estudo em três partes distintas: a primeira, na qual se trabalhará a noção de desenvolvimento a partir de Amartya Sen, tendo como pressuposto lógico a expansão das liberdades; a segunda, quando serão vistos os conceitos de democracia e suas conexões com a expansão das liberdades (especialmente as civis e políticas) e, por último, serão avaliadas as possibilidades de desenvolvimento em ambientes não (ou menos) democráticos, utilizando-se como complemento a análise empírica de países assim considerados e que, em tese, vêm incrementando seus níveis de bem-estar ou os seus níveis de desenvolvimento humano.

Por fim, realizados os estudos nos tópicos descritos, espera-se poder concluir o objeto do artigo, que é estabelecer se (e de que forma) é possível conciliar as premissas do desenvolvimento como expansão das liberdades em ambientes não (ou menos) democráticos e se (e em que medida) os países não (ou menos) democráticos atingirão esses ideais desenvolvimentistas.

\section{A NOÇÃO DE DESENVOLVIMENTO COMO LIBERDADE A PARTIR DAS TEORIAS DE AMARTYA SEN}

O tópico inicial do artigo objetiva fazer uma abordagem conceitual da noção de desenvolvimento como liberdade a partir da obra de Amartya Sen. Não se pretenderá, neste momento, oferecer definições, mas sim reflexões, sistematizar conceitos, bem como estabelecer diferenças da abordagem do referido autor em relação a outras. Assim, primeiramente, cabe fixar determinados critérios para que se possa construir a noção de desenvolvimento preconizada pelo autor.

Historicamente, o termo desenvolvimento foi empregado pela primeira vez no período da Grande Depressão, em 1929, quando a própria crise do capitalismo demandou uma avaliação sobre a necessidade de intervenção do Estado na seara econômica, moldando a economia de forma a gerar crescimento econômico (que tinha correspondência direta com uma noção inicial de desenvolvimento). Nesse período, como a classificação dos Estados entre ricos e pobres tinha conexão direta com os seus respectivos índices de crescimento econômico, 
era inevitável afirmar que aquele com o maior índice de desenvolvimento era exatamente o mesmo com o maior crescimento econômico e, portanto, o mais rico (SOUZA, 1999, p. 45).

Nesse sentido, a riqueza e o desenvolvimento eram conceitos sinônimos ou, no mínimo, correlatos, tendo em vista que aquele era visto como progresso econômico, crescimento pelo viés econômico, tudo perceptível e calculável por meio de uma análise meramente quantitativa ou numérica com correspondência direta ao aumento ou diminuição do Produto Interno Bruto (PIB) (WBATUBA, 2015, p. 33-50).

Esse entendimento acabou sendo paulatinamente modificado, especialmente ao final da Segunda Guerra Mundial, em 1945, com uma espécie de humanização que foi concretizada a partir da constatação dos horrores produzidos por aquele conflito. Assim, duas ideias centrais ganharam força e relacionaram-se, o desenvolvimento e os direitos humanos (SACHS, 2009 , p. 47), destacando-se que essas ideias principais serviram de base para a adoção de novos padrões internacionais (como a Declaração Universal dos Direitos Humanos, incorporada pelas Nações Unidas em 10 de dezembro de 1948) e para uma visão de desenvolvimento para além de mero crescimento econômico ou de progresso exclusivo na seara econômica.

Nesse sentido, diz Ignacy Sachs que

...o desenvolvimento, distinto do crescimento econômico, cumpre esse requisito, na medida em que os objetivos do desenvolvimento vão bem além da mera multiplicação da riqueza material. O crescimento é uma condição necessária, mas de forma alguma suficiente (muito menos é um objetivo em si mesmo), para se alcançar a meta de uma vida melhor, mais feliz e mais completa para todos (2008, p. 13).

Na seara internacional, a Resolução 1.161, da Assembleia Geral da Organização das Nações Unidas, ${ }^{1}$ pela primeira vez reconheceu uma conexão entre os problemas econômicos e o desenvolvimento social, assim como as interações existentes entre esses conceitos e a promoção da paz, o progresso social, a busca por melhores condições de vida, o respeito aos direitos humanos e também às liberdades fundamentais das pessoas. No mesmo sentido, tem-se que as Conferências Internacionais sobre os Direitos Humanos, em 1968 e em 1969, foram expressas ao ampliar o critério econômico que então vigorava, interligando-o a toda uma sorte de direitos, tais como os direitos civis, políticos, sociais e culturais, que foram conectados ao conceito de desenvolvimento econômico e social, previsto na Resolução 2.542 da Assembleia Geral da Organização das Nações Unidas. ${ }^{2}$

\footnotetext{
O texto da referida resolução diz expressamente que: “...that problems of economic and social development interact upon each other (...) realizing that a balanced and integrated economic and social development would contribute towards the promotion and maintenance of peace and security, social progress and better standards of living, and the observance of, and respect for, human rights and fundamental freedoms for all..." Em tradução livre, tem-se que: "os problemas do desenvolvimento econômico e social interagem uns com os outros (...) percebendo que um desenvolvimento econômico e social equilibrado e integrado contribuiria para a promoção e manutenção da paz e da segurança, progresso social e melhores condições de vida, e a observância e respeito pelos direitos humanos e liberdades fundamentais para todos..." Disponível em: <http://www.un.org/documents/ga/res/12/ares12.htm> Acesso em: 24 nov. 2018.

2 Nos objetivos da referida Resolução constava que: “...social progress and development shall aim at the continuous raising of the material and spiritual standards of living all members of society, with respect for and in compliance with human rights and fundamental freedoms..." Em tradução livre, tem-se que: "...o progresso e desenvolvimento social devem mirar no contínuo incremento das condições materiais e espirituais de todos os membros da sociedade, com respeito e obediência aos direitos humanos e liberdades fundamentais. Disponível em: <http://www.un.org/documents/ga/res/24/ares24. htm> Acesso em: 24 nov. 2018
} 
Na sequência, com a crescente percepção de uma crise ambiental que passava a ser visível pelo consumo acelerado dos recursos naturais existentes, não demorou para que um viés ambiental contaminasse positivamente a noção de desenvolvimento que se modificou nos anos anteriores. Em 1979, com a Carta Africana dos Direitos Humanos e dos Povos, ${ }^{3}$ o desenvolvimento foi concebido por um viés econômico, social e cultural, incluindo-se um elo indissociável com o meio ambiente. E mais, com a Resolução 41/128, de 1986, ficou estabelecida a Declaração sobre o Direito ao Desenvolvimento, em que o direito ao desenvolvimento foi alçado ao status de direito fundamental, gerando, como consequência, uma verdadeira obrigação para todos os Estados; ou seja, os Estados são compelidos a uma atuação específica por determinada forma, observando-se que o descumprimento acarreta algo além da simples violação a um dever ético ou moral (FERREIRA; PELLEGRINELLO, 2014, p. 376-398).

Aliás, o Relatório de Brundtland, em 1987, deu bases a uma premissa de sustentabilidade, caracterizada principalmente pelo não comprometimento das capacidades das gerações futuras de se desenvolverem mediante o uso razoável ou minimamente adequado dos recursos naturais. E essa era uma guinada necessária, como bem esclareceram Roberto Guimarães e Yuna Fontoura:

...o entendimento adequado sobre a transição impõe o reconhecimento de que a humanidade aproxima-se rapidamente, se é que já não sofre os resultados, do esgotamento de um estilo de desenvolvimento ecologicamente depredador (exaurindo a base natural de recursos), socialmente perverso (gerando pobreza e desigualdade), politicamente injusto (congelando a escassez relativa e absoluta no acesso aos recursos), eticamente reprovável (desrespeitando as formas de vida humana e não humanas) e culturalmente alienado (produzindo o estranhamento entre os seres humanos e subjugando a natureza). Por conseguinte, afirmar que os seres humanos devem constituir o centro e a razão de ser do desenvolvimento, antes de constituir o pejorativamente classificado como oximoro da sustentabilidade, implica advogar um novo estilo de desenvolvimento. Um desenvolvimento que seja ambientalmente sustentável no acesso e uso dos recursos naturais e na preservação da biodiversidade; que seja socialmente sustentável na redução da pobreza e da desigualdade e que promova a justiça social; que seja culturalmente sustentável na conservação do sistema de valores, práticas e símbolos de identidade que determinam a integração nacional através do tempo; e que seja politicamente sustentável ao aprofundar a democracia e garantir o acesso e a participação de todos os setores da sociedade na tomada de decisões (2012, p. 508-532).

A partir dessas considerações, é possível afirmar que o conceito de desenvolvimento está em constante atualização e é atualmente marcado pela sustentabilidade, revelando-se especialmente por seus vieses econômico, social e ambiental, mas igualmente sem desconsiderar tantos outros, como o viés cultural, político ou territorial, ou ainda outros ou tantos quantos forem possíveis ou necessários à efetivação dos direitos fundamentais correlacionados (FERREIRA; GODOY, 2014, p. 64-85). E essa conclusão preliminar sobre o conceito está

\footnotetext{
Artigo 22. 1. Todos os povos têm direito ao seu desenvolvimento econômico, social e cultural, no estrito respeito da sua liberdade e da sua identidade, e ao gozo igual do patrimônio comum da humanidade. 2 . Os Estados têm o dever, separadamente ou em cooperação, de assegurar o exercício do direito ao desenvolvimento. Artigo 24. Todos os povos têm direito a um meio ambiente geral satisfatório, propício ao seu desenvolvimento. Disponível em: http://www.achpr.org. Acesso em: 13 set. 2017.
} 
perfeitamente conectada à teoria do desenvolvimento de Amartya Sen, como pode ser observado nas linhas seguintes.

Logo de início, estabelece o referido autor um conceito de desenvolvimento como e enquanto expansão das liberdades substanciais; ou seja, caracteriza aquele como "um processo de expansão das liberdades reais que as pessoas desfrutam. Nesta abordagem, a expansão da liberdade é considerada (1) o fim primordial e (2) o principal meio do desenvolvimento" (SEN, 2000, p. 52). E, ainda, essas liberdades que são descritas como um fim e também um meio para o desenvolvimento não ficam resumidas ao imprescindível, ao mínimo ou ao estritamente necessário, tampouco se esgotam, por exemplo, com garantias basilares, como o direito à vida, integridade física, direito à subsistência e outros; ao revés, essas liberdades, inicialmente vistas como liberdades instrumentais, incluem toda uma sorte de liberdades políticas (como a escolha do governo, dos partidos políticos e suas características, escolha dos princípios que regerão a conduta governamental e, ao fim e ao cabo, o direito de fiscalizar e criticar a atuação estatal), de liberdades econômicas (como a disponibilidade de recursos, a possibilidade e a facilidade para produção e circulação de riquezas, além de toda gama de direitos inerentes à propriedade dos meios produtivos), liberdades e garantias sociais (como as garantias à saúde e educação), liberdades conectadas ao direito à transparência (como as garantias que se relacionam à proibição da corrupção, irresponsabilidade financeira do Estado e, enfim, às transações ilícitas) e, por último, também as liberdades e garantias de viés assistencial ou protetor (como os benefícios aos desempregados e redução da miséria). Por fim, deve-se lembrar que todas essas liberdades instrumentais conectam-se e retroalimentam o sistema de liberdades descrito pelo autor, aumentando a capacidade dos indivíduos de atingir seus próprios objetivos e alcançar, assim, a sua própria felicidade. Há, dentro dessa linha, um incremento da autonomia dos agentes no próprio processo de desenvolvimento e de busca por maior bem-estar (SEN, 2000, p. 54-57).

O desenvolvimento, tal como visto por sua evolução histórica e dentro das premissas aceitas no campo internacional, é compatível com a visão pela expansão das liberdades e pela interconexão entre os diversos tipos de liberdades e garantias que, como dito, são meio e fim do próprio sistema de liberdades, tendo em vista que a teoria de Amartya Sen de fato conduz a uma ideia de que há efetivamente uma lacuna entre a perspectiva da concentração de riqueza e a vida que os indivíduos almejam e realizam; ou seja, da mesma forma que na visão internacional, a simples acumulação da riqueza não corresponde ao desenvolvimento que se busca (SEN, 2000, p. 3-14). Para o autor, o desenvolvimento vai além e está intimamente ligado à capacidade do indivíduo de atingir seus objetivos e alcançar a felicidade. Para tanto, devem ser fornecidos os instrumentos necessários, ou seja, as liberdades políticas, facilidades econômicas, liberdades e oportunidades sociais, garantias de transparência e liberdades assistenciais ou protetoras. Do mesmo modo, quanto maior a liberdade, maior o desenvolvimento; assim, a liberdade alimenta o desenvolvimento que retroalimenta a própria liberdade (SEN, 2000, p. 59), o que deixa transparecer a existência, ou uma característica, de autopoiese, no sentido de que há um relacionamento entre os elementos (o desenvolvimento e a liberdade), uma resposta ou uma relação recursiva que denota um câmbio proporcional (GUERRA FILHO, 2009, p. 197). 
Feitas essas considerações, tem-se que o desenvolvimento coloca um papel central nas pessoas (e nas suas liberdades) como agentes de transformação; ainda, considera que fatores externos, como a pobreza, a exclusão social, a violência, o preconceito, a falta de oportunidades econômicas, a limitação na atuação político-social, entre tantos outros, podem limitar a capacidade de alcançar esse objetivo desenvolvimentista. Essas limitações podem ser suplantadas por políticas específicas que terão como foco erradicar essas fontes de privação das liberdades e, como consequência, incrementarão não só as liberdades, mas também o próprio desenvolvimento (SEN, 2000, p. 59-60), em um círculo virtuoso que, portanto, conduz à expansão das liberdades e ao desenvolvimento.

\section{OS FUNDAMENTOS DA DEMOCRACIA E SUAS CONEXÕES COM A TEORIA DO DESENVOLVIMENTO}

No primeiro tópico viu-se que o conceito de desenvolvimento é histórico e multifacetado e que, ao se conectarem as ideais de desenvolvimento à visão de Amartya Sen, surge cristalina uma imagem de liberdade (e de expansão das liberdades como meio e fim do desenvolvimento); ou seja, exerce a liberdade um papel fundamental no conceito de desenvolvimento, destacando-se que a expansão dessas liberdades, especialmente as liberdades civis e políticas, no caso de ambientes democráticos, é ao mesmo tempo meio e fim para a concretização dos ideais desenvolvimentistas. Assim, partindo dessa constatação inicial, importante averiguar o próprio conceito de democracia, a fim de tornar possível, no último tópico do artigo, o exercício da crítica sobre a possibilidade de desenvolvimento e, consequentemente, de uma expansão das liberdades, em ambientes não (ou menos) democráticos.

A doutrina nacional consolidou um entendimento basilar no sentido de que a democracia pode ser subdividida em não representativa e representativa. A primeira, com nascedouro na Grécia, parte do pressuposto de que o próprio povo deve exercer o poder político de forma direta, pessoal e imediata; ou seja, as pessoas, reunidas em praça pública (ou no Ágora, como na Grécia Antiga), tomam as decisões políticas e exercem o poder político sem qualquer forma de intermediação (pessoal e diretamente, portanto) (BONAVIDES, 2000, p. 318).

A segunda forma de democracia, a não representativa, surge pela desvalorização dessa ideia de participação direta no processo político e pela consolidação do capitalismo, que acabou por afastar o homem da vida pública. Nesse modelo, ainda que o poder permaneça com o povo, há uma autorização para que o exercício desse poder fique relegado a seus representantes, que atuarão em nome daquele (BONAVIDES, 2000, p. 330).

Note-se, nesse ponto, que não se trata somente de autorização popular (no sentido de consentimento legal para o exercício do poder), mas também de legitimidade para tanto e que vai além da simples averiguação da legalidade. Ao contrário do que defende Maurice Hauriou (1927, p. 198), por exemplo, o exercício legítimo do poder não depende apenas da forma de aquisição e transmissão ou do império da lei; ao revés, para além da questão jurídico-formal, há que se incluir um viés de substância, um contexto material ou ideológico que fica automaticamente vinculado a uma ordem político-constitucional que corresponde aos anseios do próprio povo (DUVERGER, 1976, p. 39). Dito de outro modo, as democracias representativas modernas devem ser vistas como legítimas quando, para além da autorização ou consentimento para a delegação do exercício do poder, for constatada uma conexão intrínse- 
ca entre a atuação dos representantes e os anseios do povo, ou uma atuação justa, correta e adequada, com uma parcela de aceitação mínima da própria sociedade representada.

Por isso a democracia, independentemente da sua classificação, não pode ser tratada meramente como uma decisão majoritária, mas sim uma decisão majoritária legítima (DWORKIN, 1995, p. 2). ${ }^{4}$ Há, nesse sentido, uma íntima relação entre a democracia e o constitucionalismo. Para a doutrina, o constitucionalismo

...tem origem nos Estados Unidos a partir da ideia do rule of law, no sentido de que é necessária a preservação de determinadas regras jurídicas fundamentais, limitadoras do poder estatal (e limitadoras, em última análise, do poder do próprio povo). O governo, além de se encontrar com limitações, está adstrito a normas (regras e princípios) jurídico-constitucionais, daí a necessidade de existência de uma Constituição que expressa não apenas o mundo do ser, mas também do dever-ser, e por isso essa Constituição deve ser protegida por mecanismos complexos de eventual modificação (PASTRE, 2015, p. 93-94).

Assim, certos limites constitucionais ao exercício do poder não maculam o ambiente democrático, mas sim o fortalecem; ou seja, esses limites são (e devem ser) impostos pelos próprios titulares do poder no intuito não de viciar a vontade majoritária, mas sim de possibilitar a própria existência dessa vontade, inclusive para as gerações futuras, o que conduzirá à integridade democrática (ELSTER, 2001, p. 34-35). Sendo assim, as premissas constitucionais (as garantias que traduzem o conceito de constitucionalismo) conduzem também a uma espécie de sustentabilidade democrática, no sentido de manutenção das garantias mínimas para o exercício do poder de forma democrática. Em contrapartida, a democracia atua em prol desse constitucionalismo, pressionando o sistema para o fim de enquadrá-lo à vontade popular. Desse modo, enquanto o constitucionalismo atua garantindo as regras do jogo, a democracia atualiza as próprias regras, adequando-as aos anseios populares (CHUERI; GODOY, 2010, p. 159-174).

Aliás, esse dualismo é marcante no caso brasileiro, em que o texto constitucional é reflexo direto de anterior ditadura e a redemocratização implicou uma necessidade de promover um afastamento definitivo do autoritarismo que marcava o período precedente. Na lição de Flávia Lages de Castro, o texto constitucional brasileiro é amplo e pesado, quiçá prolixo, porque trata de parte de questões que poderiam ser relegadas à legislação ordinária. Ao que parece, a enciclopédia constitucional advém de um medo da volta aos tempos mais sombrios que permanecem latentes na memória do povo (CASTRO, 2009, p. 564). Na síntese, o constituinte brasileiro preocupou-se em dotar certos bens jurídicos de proteção especial, lançando mão da rigidez constitucional como ferramenta contra a arbitrariedade (ou ao exercício do poder arbitrário ou autoritário em uma democracia caracterizada pela representatividade),

\footnotetext{
Diz o autor que há "distinction between democracy and majoritary rule. Democracy means legitimate majoritary rule, which means that mere majoritarianism does not constitute democracy unless further conditions are met. It is controversial just what these conditions are. But some kind of constitucional structure that a majority cannot change is certainly a prerequisite to democracy. There must be embedded constitucional rules stipulating that a majority cannot abolish future elections, for example, or disenfranchise a minority". Em tradução livre, tem-se que "há uma distinção entre democracia e decisão majoritária. Democracia significa decisão majoritária legítima, o que quer dizer que majoritarismo não se constitui em democracia se determinadas condições não forem atingidas. Quais são essas condições ainda é controverso. Mas algum tipo de estrutura constitucional que a maioria não pode mudar é certamente um pré-requisito para a democracia. Deve haver regras constitucionais fixas estipulando que a maioria não pode abolir eleições futuras, por exemplo, ou privar uma minoria de seus direitos."
} 
gerando uma estabilidade com aspirações duradouras em matérias consideradas sensíveis (BONAVIDES, 2004, p. 92).

Não se ignora que esse elo entre o constitucionalismo (e a blindagem a certos temas sensíveis por mecanismos que engessam as possibilidades de alterações na Constituição Federal) e a democracia (e a característica essencial da decisão majoritária - decisão legítima, como visto) possa sofrer críticas diversas, por exemplo, a constatação de que a democracia em si é imposta por meio da força (KARSTEN; BECKMAN, 2013, p. 52-53). No caso brasileiro, no entanto, a Constituição possibilitou a extinção e consequente supressão (talvez) definitiva de um poder absoluto mediante adoção de regras vitais ao funcionamento do próprio sistema democrático (ZIPPELIUS, 1997, p. 385). Aliás, a Constituição, por estar conectada a uma estrutura de direitos e garantias fundamentais, deixa de ser uma mera representação de estrutura de poder e passa a ter uma normatividade que retrata o espírito jurídico e a identidade social do povo (no caso, o povo brasileiro), transformando a democracia política em democracia constitucional (CADENA, 2011, p. 67-95). Não obstante, cabe ressaltar que no caso brasileiro existem inúmeros obstáculos à expansão das liberdades e, portanto, ao desenvolvimento. $\mathrm{Na}$ lição de Luís Roberto Barroso, sofre a sociedade brasileira com a desigualdade

...econômica, que se materializa no abismo entre os que têm e os que não têm, com a consequente dificuldade de se estabelecer um projeto comum de sociedade. Desigualdade política, que faz com que importantes opções de políticas públicas atendam prioritariamente aos setores que detêm força eleitoral e parlamentar, mesmo quando já sejam os mais favorecidos. Desigualdade filosófica: o vício nacional de buscar o privilégio em vez do direito, aliado à incapacidade de perceber o outro, o próximo (2006, p. 63-64).

Com base em toda essa exposição, pode-se concluir que o conceito de democracia utilizado no presente estudo conecta-se ao de desenvolvimento visto pela perspectiva da expansão das liberdades; isso porque o ambiente democrático é, em si, um dos elementos constitutivos do próprio desenvolvimento (as liberdades políticas estão, portanto, inseridas no campo das liberdades intrínsecas ao conceito de desenvolvimento). No caso brasileiro, constituído por um Estado Democrático de Direito, o projeto constitucional pós-ditadura, apesar de efetivamente recente, não foi totalmente concluído (ou instituído), restando as mazelas encontradas como verdadeiros obstáculos à expansão das liberdades e, portanto, como um fator impeditivo ao desenvolvimento nacional. Ora, se na medida em que se ampliam essas liberdades também se amplia o desenvolvimento, parece correto afirmar que o projeto brasileiro está no caminho correto para atingir esses objetivos. E, se essas falhas são encontradas em um ambiente democrático, deve o estudo voltar-se a questões mais amplas e verificar as possibilidades de desenvolvimento em um ambiente não (ou menos) democrático.

\section{AVALIAÇÃO CRÍTICA DA IDEIA DE EXPANSÃO DAS LIBERDADES EM UM AMBIENTE NÃO (OU MENOS) DEMOCRÁTICO}

Nos tópicos anteriores viu-se que o desenvolvimento é visto sob uma perspectiva histórica e multifacetada; ainda, que na teoria de Amartya Sen, está intimamente conectado à liberdade (ou à expansão das liberdades), constituindo os indivíduos o foco e também os principais agentes de transformação. Do mesmo modo, em relação ao ambiente democrático, estabeleceu-se que o poder pertence ao povo, que pode (ou não) delegar o exercício a 


\section{Democracia}

representantes eleitos, caracterizando uma democracia representativa ou não representativa. E mais, verificou-se que o constitucionalismo é um importante instrumento para preservação do ambiente democrático, transformando a democracia em uma fonte de decisões majoritárias legítimas (conectadas ao anseio popular, mas também às diretrizes constitucionais mais básica que visam a garantir direitos fundamentais e a manutenção do citado ambiente democrático).

Para possibilitar uma visão crítica sobre as possibilidades de desenvolvimento e, consequentemente, de expansão das liberdades, em ambientes não (ou menos) democráticos, necessário estabelecer uma perspectiva inicial sobre as características desses ambientes. $\mathrm{Na}$ lição clássica de Paulo Bonavides, a democracia vale-se da separação ou das relações entre os poderes do Estado, enquanto a ruptura desse padrão acarreta uma ditadura, que parte do pressuposto da concentração daqueles poderes nas mãos de uma pessoa ou grupo político (BONAVIDES, 2000, p. 256). Nessa linha, a Organização Não Governamental (ONG) Freedom House disponibiliza anualmente um relatório demonstrando a existência de 49 (quarenta e nove) ditaduras para o ano de 2018, destacando-se os casos de três países específicos: China, Cuba e Venezuela. ${ }^{5}$

Os países citados possuem, todos, um ordenamento jurídico-constitucional. No caso da China, o artigo 2. da Constituição da República Popular da China descreve um Estado socialista subordinado à ditadura democrático-popular da classe operária (CHU, 2000, p. 687-721). ${ }^{6} \mathrm{~A}$ ilha de Cuba, por outro lado, estabelece-se logo no artigo 1. da Constituição da República de Cuba, ${ }^{7}$ como uma República Unitária e Democrática. Por fim, no caso da Venezuela, o artigo 2. da Constituição da República Bolivariana da Venezuela, diz que a Venezuela se constitui em um Estado Democrático e Social de Direito e de Justiça, que, entre outros valores, preza pela democracia. ${ }^{8}$ Mesmo, todavia, no caso dos países que se denominam democráticos, convém ressaltar que não existe verdadeira democracia (ou democracia real, não a formal) em um ambiente sem alternância de poder (ou sem possibilidade de alternância) ou sem oposição ao poder. Nesse sentido, estabelece Tarcisio Vieira de Carvalho Neto que:

\footnotetext{
O Freedom's House Annual Report está disponível em: https://planetrulers.com/wp-content/uploads/2018/04/freedom-in-the-world-2018-report-freedom-house-planetrulers.pdf Acesso em: 23 nov. 2018.

6 Diz o artigo 2. da Constituição da República Popular da China, que "A República Popular da China é um Estado socialista subordinado à ditadura democrático-popular da classe operária e assente na aliança dos operários e camponeses. $\mathrm{O}$ sistema socialista é o sistema básico da República Popular da China. É proibida a sabotagem do sistema socialista por qualquer organização ou indivíduo." CHU, José. Constituição da República Popular da China. Revista Administração Pública, vol. 13, n. 48, p. $687-721,2000$

Diz o artigo 1. da Constituição da República de Cuba, que "Cuba es un Estado socialista de trabajadores, independiente y soberano, organizado con todos y para el bien de todos, como República unitaria y democrática, para el disfrute de la libertad política, la justicia social, el bienestar individual y colectivo y la solidaridad humana." Em tradução libre: "Cuba é um Estado socialista de trabalhadores, independente e soberano, organizado com todos e para o bem de todos, como uma República unitária e democrática, para o gozo da liberdade política, da justiça social, do bem-estar individual e coletivo e da solidariedade humana."

8 Diz o artigo 2.o da Constituição da República Bolivariana da Venezuela, que "Venezuela se constituye en un Estado democrático y social de Derecho y de Justicia, que propugna como valores superiores de su ordenamiento jurídico y de su actuación, la vida, la libertad, la justicia, la igualdad, la solidaridad, la democracia, la responsabilidad social y en general, la preeminencia de los derechos humanos, la ética y el pluralismo político." Em tradução livre: "Venezuela se constitui em um Estado Democrático e Social de Direito e de Justiça, que propugna como valores superiores de seu ordenamento jurídico e de sua ação, a vida, a liberdade, a justiça, a igualdade, a solidariedade, a democracia, a responsabilidade social em geral, a preeminência dos direitos humanos, a ética eo pluralismo político."
} 


\section{Democracia}

...a alternância não é propriamente um princípio fundante da democracia, mas sim elemento integrante (e vital!) da oposição. Assim, pode haver oposição sem alternância, quando a oposição é fraca ou mesmo quando o povo está satisfeito com a situação. Também pode haver, em tese, democracia sem alternância, embora, em tal contexto, a tendência seja a de desnaturação progressiva da primeira, de sua convolação de democracia real em formal. O que não pode haver, absolutamente, é democracia sem oposição. Isto, sim, parece inegociável. O ideal, intuitivo supor, é democracia (real) com oposição (construtiva). E oposição (construtiva) com alternância substancial, esta última entendida não como aquela que propõe trocas formais, de personagens e pessoas por pessoas e personagens do mesmo grupo de interesses, mas que consubstancie, a serviço do titular do poder, o povo, a revisão real do quadro político e, com isso, se preste a redefinir, para qualquer dos lados, os rumos da nação (CARVALHO NETO, 2012, p. 175).

De qualquer modo, independentemente de caracterizados os países citados como democracias formais ou ditaduras, é preciso verificar e eventualmente contrapor o conceito (e as possibilidades) de desenvolvimento nos referidos regimes, caracterizados como não (ou menos) democráticos. Uma das possibilidades é avaliar o quadro comparativo do Índice de Desenvolvimento Humano (IDH), disponibilizado pelas Nações Unidas. No referido, o Brasil aparece em 79ㅇ lugar, atrás de Cuba, em 73ㅇ, e da Venezuela, em 78, mas na frente da China, em 860; porém nas últimas três décadas (de 1990 até agora), o país que mais cresceu no índice foi a China $(0,250)$, depois Brasil $(0,148)$, Venezuela $(0,127)$ e Cuba $(0,101){ }^{9}$

O sucesso da China, que cresceu no Índice de Desenvolvimento Humano (IDH) mais do que o dobro do que a ilha de Cuba, deu-se, segundo a própria doutrina chinesa, em razão de uma busca incessante pelo desenvolvimento sob a perspectiva predominantemente econômica, como políticas voltadas à abertura dos mercados, ao crescimento e modernização da agricultura, da indústria, das Forças Armadas e da ciência e tecnologias, e, em última análise, ao incremento do Produto Interno Bruto (PIB), que passou a ser o segundo maior do mundo (OURIQUES, 2013, p. 83); ou seja, da tese de que é o desenvolvimento econômico e social que acabaria por gerar avanços no que diz respeito aos direitos humanos ou à dignidade da pessoa humana, e não o contrário (COELHO; COELHO; DINIZ, 2017, p. 2016).

$E$ a referida tese é factível, considerando que no lado cubano até mesmo os atos mais simples, como o acesso à informação ou aos meios de comunicação (como a Internet), está absolutamente maculado pelo regime ditatorial. Na lição de Michel D. Suárez Sian, o panorama para a mídia e para a tecnologia em Cuba é sombrio, tornando-se a ilha incapaz de enfrentar a competitividade econômica na sociedade globalizada, inclusive em razão do embargo econômico, que restringe econômica e tecnologicamente a informação e, via de consequência, alimenta o álibi do próprio governo cubano (SIAN, 2012, p. 12).

Nos termos dos exemplos antes mencionados, torna-se patente que as liberdades instrumentais, na visão de Amartya Sen, como as liberdades econômicas (como produção e circulação de riquezas), as liberdades e garantias sociais (como o acesso à educação e novas tecnologias) ou outras, como aquelas vinculadas à transparência ou à assistência social (com foco na redução da pobreza, por exemplo), são essenciais para a concretização do desenvol-

\footnotetext{
O relatório completo está disponível em: http://hdr.undp.org/sites/default/files/2018_human_development_statistical_ update.pdf. Acesso em: 23 nov. 2018.
} 
vimento em todos os seus aspectos (no caso, os vieses econômico, social, ambiental, cultural, político ou territorial, ou outros, como visto). E mais, as liberdades políticas e de transparência (ou, em geral, de informação), enquanto são incompatíveis com um sistema ditatorial, são e serão obstáculos instransponíveis ao pleno desenvolvimento, ainda que este seja alcançado na trilha econômica; ou seja, sem desconsiderar que um rápido crescimento econômico pode gerar receita para que o Estado possa aplacar outras mazelas sociais (expandindo certas liberdades instrumentais), o mero crescimento é incapaz de consolidar o ideal de desenvolvimento. No resumo de Amartya Sen:

...temos de ir além do crescimento econômico para entender as exigências completas do desenvolvimento e da busca do bem-estar social. Deve ser dada atenção à ampla evidência de que a democracia e os direitos políticos e civis tendem a reforçar as liberdades de outros tipos (como a segurança humana) ao dar voz, pelo menos em muitas circunstâncias, aos carentes e vulneráveis. Essa é uma importante questão, intimamente ligada ao papel da democracia na argumentação pública e na promoção do "governo por meio do debate". O êxito da democracia na prevenção das fomes coletivas pertence às múltiplas contribuições da democracia para a promoção da segurança humana, mas também há muitos outros campos de aplicação. O poder protetor da democracia na provisão de segurança é, na verdade, muito mais amplo do que na prevenção da fome. Nos anos 1980 e início dos 1990, durante o boom econômico na Coreia do Sul ou na Indonésia, quando a situação econômica de todos parecia melhorar a cada dia, os pobres podem não ter pensado muito na democracia, mas quando vieram as crises econômicas (precipitando a divisão social) no fim dos anos 1990, aqueles cujas vidas e meios econômicos foram incomumente golpeados sentiram desesperadamente a falta da democracia e dos direitos políticos e civis. A democracia de repente se tornou uma questão central nesses países, com a Coreia do Sul tendo uma grande iniciativa nesse sentido... É difícil escapar da conclusão geral de que o desempenho econômico, a oportunidade social, a voz política e a argumentação racional pública estão profundamente inter-relacionados (SEN, 2011, p. 385-386).

Pelo exposto, ficou demonstrado que ainda que seja possível o crescimento econômico (a expansão das liberdades econômicas, acesso a bens de consumo, facilidade na produção e nas trocas) e ainda que esse crescimento seja capaz de fomentar a erradicação de mazelas graves e, assim, gerar a expansão de outras liberdades, não há desenvolvimento pleno, no sentido atribuído por Amartya Sen, quando inexistente um ambiente democrático, tendo em vista uma relação de incentivos e também de interdependência entre meios e fins do desenvolvimento, ou entre as liberdades econômicas e as demais, como as políticas, de transparência ou de seguridade social (as protetoras, na visão de Sen).

\section{CONCLUSÃO}

A proposta inicial do artigo era avaliar o conceito de desenvolvimento a partir das lições de Amartya Sen e fazer uma conexão entre o referido à democracia, permitindo verificar se era possível a coexistência de desenvolvimento e ditadura, ou da existência de algum nível de desenvolvimento em ambientes não (ou menos) democráticos). Do mesmo modo, objetivava-se concluir se a democracia poderia ser um empecilho ao desenvolvimento ou se, ao revés, era de sua própria essência. 
No primeiro item concluiu-se que, para Amartya Sen, o desenvolvimento coloca um papel central nas pessoas (e nas suas liberdades) como agentes de transformação; igualmente, considera que fatores externos, como a pobreza, a exclusão social, a violência, o preconceito, a falta de oportunidades econômicas, a limitação na atuação político-social, entre tantos outros, podem limitar a capacidade de alcançar esse objetivo desenvolvimentista. Já no segundo tópico viu-se que o conceito de democracia conecta-se ao de desenvolvimento visto pela perspectiva da expansão das liberdades; isso porque o ambiente democrático é, em si, um dos elementos constitutivos do próprio desenvolvimento.

A conclusão final, portanto, é de que é possível gerar crescimento econômico em ambientes não (ou menos) democráticos, assim como promover o desenvolvimento econômico, que se dará por meio de resultados positivos substanciais macroeconômicos, aliado ao aumento da capacidade produtiva do país; entretanto, as limitações à expansão das liberdades somente poderão ser suplantadas por políticas específicas que dependem, senão totalmente da existência de democracia, ao menos minimamente de liberdades políticas, de transparência e protetoras, sem as quais a voz dos agentes de transformação permanecerão silenciadas e, ao final, esquecidas.

\section{REFERÊNCIAS}

BARROSO, Luís Roberto. Fundamentos teóricos e filosóficos do novo Direito Constitucional brasileiro - pós-modernidade, teoria crítica e pós-positivismo. In: QUARESMA, Regina; OLIVEIRA, Maria Lúcia de Paula (org.). Direito constitucional brasileiro: perspectivas e controvérsias contemporâneas. Rio de Janeiro: Forense, 2006.

BHAGWATI, Jagdish N. Democracy and Development: Cruel Dilemma or Symbiotic Relationship? Review of Development Economics, v. 6, p. 151-162, 2002.

BOBBIO, Norberto. O futuro da democracia: uma defesa das regras do jogo. Tradução Marco Aurélio Nogueira. Rio de Janeiro: Paz e Terra, 1986.

BONAVIDES, Paulo. Ciência política. 10. ed. São Paulo: Malheiros, 2000.

BONAVIDES, Paulo. Curso de Direito Constitucional. 15. ed. São Paulo: Malheiros, 2004.

CADENA, Grenfieth de Jesús Sierra. La Justicia Constitucional en la Era de la Gobernanza: un análisis de perspectiva comparada desde la periferia del derecho. Revista de Filosofía, Derecho y Política, n. 13, jan. 2011.

CARVALHO NETO, Tarcisio Vieira de. O Princípio da Alternância no Regime Democrático. Revista de Informação Legislativa, Brasília, a. 49, n. 196, p. 165-96, out./dez. 2012.

CASTRO, Flávia Lages de. História do Direito Geral e do Brasil. 7. ed. Rio de Janeiro: Lumen Juris, 2009.

CHUEIRI, Vera Karam de; GODOY, Miguel G. Constitucionalismo e democracia: soberania e poder constituinte. Revista de Direito GV, São Paulo, v. 6, n. 1, p. 159-174, jun. 2010.

COELHO, Diva Julia Sousa da Cunha Safe; COELHO, Saulo de Oliveira Pinto; DINIZ, Ricardo Martins Spindola. Constituição, constitucionalismo e efetividade na China: ilações entre cultura tradicional, práxis política e discurso constitucionalista no contexto chinês. Revista da Faculdade de Direito da UFPR, Curitiba, v. 62, n. 3, p. 187220, set./dez. 2017.

DUVERGER, Maurice. Ciência política: teoria e método. Trad. Heloísa de Castro Lima. 2. ed. Rio de Janeiro: Zahar Editores, 1976.

DWORKIN, Ronald. Constitucionalism and Democracy. European Journal of Philosophy, v. 3, n. 1, p. 2-11, 1995.

ELSTER, Jon. Constitucionalismo y Democracia. México: Fondo de Cultura Económica, 2001.

FERREIRA, Daniel; GODOY, Maria Ivone. O meio ambiente laboral frente à maximização da responsabilidade socioambiental das empresas. In: MEZZAROBA, Orides. Direitos especiais e tutela das minorias na atividade empresarial. Curitiba: Conpedi, 2014. V. 22.

FERREIRA, Daniel; PELLEGRINELLO, Ana Paula. Grandes obras, grandes impactos e a promoção (controlada e controlável) do desenvolvimento nacional sustentável. Revista Jurídica - Unicuritiba, Curitiba, v. 1, n. $34,2014$. GUERRA FILHO, Willis Santiago. Teoria da ciência jurídica. 2. ed. São Paulo: Saraiva, 2009. 
GUIMARÃES, Roberto; FONTOURA, Yuna. Desenvolvimento sustentável na Rio+20: discursos, avanços, retrocessos e novas perspectivas. Cadernos EBAPE.BR, Rio de Janeiro, v. 10, n. 3, set. 2012.

HAURIOU, Maurice. Principios de Derecho Público y Constitucional. 2. ed. Madrid: Instituto Editorial Reus, 1927. KANT, I. Crítica da razão prática. Trad. Valério Rohden. São Paulo: Martins Fontes, 2003.

KARSTEN, Frank; BECKMAN, Karel. Além da democracia. Trad. Fernando M. Ferreira. São Paulo: Instituto Ludwing Von Misses, 2013.

MARRARA, Thiago. O conteúdo do princípio da moralidade: probidade, razoabilidade e cooperação. Revista Digital de Direito Administrativo, São Paulo, v. 3, n. 1, 2016.

MILL, John Stuart. A liberdade; utilitarismo. São Paulo: Martins Fontes, 2000.

OURIQUES, Helton Ricardo. O ressurgimento da China e suas consequências para a América Latina e o Brasil. In: VIEIRA, Rosângela de Lima. O Brasil, a China e os EUA na atual conjuntura da economia-mundo capitalista. São Paulo: Cultura Acadêmica, 2013.

PASTRE, Daniel Fernando. Constitucionalismo e democracia no Brasil: a libertação da maioria do domínio de uma minoria por mecanismos constitucionais de participação popular. Ciências Sociais Aplicadas em Revista, Unioeste/MCR, v. 15, n. 28, p. 90-107, jan./jun. 2015.

RICHARDSON, Roberto Jarry. Pesquisa social: métodos e técnicas. 3. ed. rev. e atual. São Paulo: Atlas, 2012.

ROCHA, Cármen Lúcia Antunes (org.). Direito à vida digna. Belo Horizonte: Fórum, 2004.

SACHS, Ignacy. Caminhos para o desenvolvimento sustentável. Rio de Janeiro: Garamond, 2009.

SACHS, Ignacy. Desenvolvimento: includente, sustentável, sustentado. Rio de Janeiro: Garamond, 2008.

SANDEL, Michael J. Justiça: o que é fazer a coisa certa. São Paulo: Editora José Olympio, 2015.

SEN, Amartya. A ideia de justiça. Trad. Denise Bottmann e Ricardo Doninelli Mendes. São Paulo: Companhia das Letras, 2011.

SEN, Amartya. Desenvolvimento como liberdade. Trad. Laura Teixeira Motta. São Paulo: Companhia das Letras, 2000.

SIAN, Michel D. Suárez. Cuba: internet, acceso y sociedad del conocimiento. Razón y Palabra, v. 17, n. 81, nov./ enero, 2012.

SOUZA, Nali Jesus de. Desenvolvimento econômico. 3. ed. São Paulo: Atlas, 1999.

WALZER, Michael. Esferas da justiça: uma defesa do pluralismo e da igualdade. Tradução Jussara Simões. São Paulo: Martins Fontes, 2003.

WBATUBA, Berenice Beatriz Rossner; DEPONT, Cidônea Machado; SEIBERT, Rosane Maria. A questão ambiental e o desenvolvimento sustentável: um estudo exploratório com base nos fundamentos das teorias institucional e legitimidade. Revista do Desenvolvimento Regional, Taquara, v. 12, n. 2, jul./dez. 2015.

ZIPPELIUS, Reinhold. Teoria geral do Estado. Trad. Karin Praefke-Aires Coutinho. 3. ed. Lisboa: Fundação Calouste Gulbekian, 1997. 